\title{
¿Víctimas virtuales? Inseguridad, públicos y redes sociales en Argentina
}

\section{Virtual victims? Insecurity, audiences and social networking services in Argentina}

\section{SANTIAGO GALAR}

santiago galar@hotmail.com - Centro Interdisciplinario de Metodología de las Ciencias Sociales, Universidad Nacional de La Plata y Consejo Nacional de Investigaciones Científicas y Técnicas (CONICET), Argentina.

\section{BRENDAFOCÁS}

bfocas@conicet.gov.ar - Instituto de Altos Estudios Sociales, Universidad Nacional de San Martin (IDAES-UNSAM) y Consejo Nacional de Investigaciones Científicas y Técnicas (CONICET), Argentina.

Fecha de recepción: 10 de marzo de 2018 Fecha de aceptación: 10 de abril de 2018

\section{RESUMEN}

Internet se transformó en los últimos años en una plataforma de procesos de interacción online que amplió la posibilidad de participación a usuarios/as no expertos. En ese contexto, la inseguridad, como issue, constituyó un tema usual para su difusión y debate por espacios virtuales. En el presente artículo nos proponemos indagar sobre las prácticas en redes sociales ejercidas por públicos que se conforman alrededor de la inseguridad en Argentina durante la última década, atendiendo particularmente a las prácticas de aquellos/as familiares de víctimas del delito. Con este objetivo indagamos sobre diversas experiencias: en primer lugar, analizamos prácticas y contenidos emergentes de tres espacios en redes sociales vinculados a casos de inseguridad. En segundo lugar, realizamos entrevistas en profundidad con administradores/as de diversas páginas (o fanpages) y grupos abiertos de Facebook vinculados a la experiencia de la victimización y la inseguridad. Finalmente, partici- pamos de acciones colectivas callejeras vinculadas a la organización y demanda de estos grupos virtuales, particularmente una marcha por seguridad. El trabajo se centra en las dinámicas de los procesos que confluyen en estas experiencias y en las prácticas de los actores que les dan entidad, sobre los cuales realizamos un análisis de tipo cualitativo.

PALABRAS CLAVE: redes sociales, espacio público, inseguridad, activismo, públicos.

\section{ABSTRACT}

Recently, the Internet has become a platform for online interaction processes that has expanded the possibility of participation to non-expert users. In this context, insecurity, as an issue, has become in a common theme for its dissemination and debate through virtual spaces. In this article we propose to investigate the practices in social networking services exercised by publics that are shaped around insecurity in Argentina during the last decade, paying particular attention to the practices of those relatives of victims of crime. With this objective we investigate different experiences: firstly, we analyze practices and emerging contents of three spaces in social networking services linked to cases of insecurity. Secondly, we conducted in-depth interviews with administrators from different pages (or fanpages) and Facebook open groups linked to the experience of victimization and insecurity. Finally, we participate in collective street actions linked to the organization and demand of these virtual groups, particularly a march for security. The work focuses on the dynamics of the processes that converge in these experiences and the practices of the actors that give them entity. We perform a qualitative analysis.

KEYWORDS: social networks, public space, insecurity, activism, publics. 


\section{INTRODUCCIÓN}

En las últimas décadas, en sintonía con lo ocurrido en diversos países latinoamericanos, la inseguridad se consolidó en Argentina como un problema público destacado, al punto de permanecer al tope de las preocupaciones ciudadanas. La inseguridad, siguiendo a Kessler (2009), se configuró más precisamente como un fenómeno que se decantó hacia un sentido ligado a un estado de indefensión despojado de precisiones, como un problema que se nutre de imágenes nostálgicas de un pasado en el cual el riesgo parece no haber existido. Como vimos en otro trabajo (Galar, 2017a), la inseguridad quedó instalada como un esquema de percepción amplio que permite agrupar en su seno hechos disímiles y con diferentes relaciones con lo delictivo.

Un factor que posibilitó la emergencia de este problema público, cabe destacar, fue la irrupción pública de activistas en demanda de seguridad. Las primeras acciones colectivas por seguridad ocurrieron a fines de los años noventa, convocadas por actores afectados de manera más o menos directa, sin obtener gran impacto público. El punto de mayor visibilidad fue el caso Blumberg, ocurrido en 2004 en el marco de una "ola de secuestros extorsivos"1. Desde entonces, la demanda por seguridad se volvió regular no sólo en la zona metropolitana de Buenos Aires, sino también en las provinciasy demostróla potencia que adquirió esa preocupación en todo el país.

Como evidenciamos durante el trabajo de campo, los actores que protestan en el espacio público en tanto víctimas de la inseguridad se presentan como damnificados por cuestiones diversas, entre ellas las mafias, el delito urbano, la corrupción, la violencia machista, los conflictos interpersonales o la irresponsabilidad vial. Son jóvenes baleados en los barrios populares, ciudadanos de clase media alta asaltados, policías "caídos" en cumplimiento del deber, niños y niñas atropellados. En términos generales, se presentan como víctimas de "hechos evitables" y señalan al Estado como el agente que debe protegerlos y procurar que el daño sea reparado. La variedad de las víctimas que interviene en el espacio público refleja la amplitud que en la última década ha adquirido la cuestión de la inseguridad.

Es en el marco de la diversidad que atraviesa a este problema que en el presente artículo nos proponemos indagar sobre las prácticas en redes sociales ejercidas por públicos que se integran en Argentina alrededor de la inseguridad durante la última década, atendiendo particularmente a las prácticas de familiares de víctimas del delito. Como es sabido, Internet se transformó en los

1 Axel Blumberg tenía 23 años el 17 de marzo de 2004, cuando fue secuestrado y luego asesinado por sus captores. El padre del joven, Juan Carlos Blumberg, convocó a una cruzada nacional en reclamo delendurecimiento delasleyes penales que resultó inédita por su masividad y repercusiones políticas. En la ciudad de Buenos Aires se realizaron multitudinarias marchas para exigir el esclarecimiento del caso y mayores controles por parte de la policía. Como consecuencia, se sancionaron varias leyes que modificaron el Código Penal, como la ley que incrementó las penas para homicidios y violaciones seguidas de muerte y aquella la que establece la pena de prisión no excarcelable para personas portadoras de armas. Sobre la construcción pública del caso, véase Calzado (2015). 
últimos años en una plataforma de procesos de interacción online que amplióla posibilidad de participación a personas no expertas (López \& Ciuffoli, 2012). La difusión de las redes sociales constituye el punto más desarrollado de estas nuevas formas de participación, un proceso tan inédito como contundente. En agosto de 2017 el número de usuarios y usuarias alcanzó la cifra de 3 mil millones, cuando la población mundial es de alrededor de 7.500 millones de habitantes, de los cuales casi 4 mil millones poseen acceso a Internet. Alrededor del 40 por ciento de quienes usan las redes, cabe destacar, acceden a ellas a través del teléfono celular ${ }^{2}$. La red social más popular es Facebook, con 2 mil millones de usuarios y usuarias activos, según números de la propia empresa. Desde 2015, cuando superó a Google, Facebook se constituyó además como la plataforma líder en redirigir lectores hacia contenidos informativos.

Las redes sociales se desarrollaron bajo el optimismo derivado de su potencial democratizador: empoderaban a la ciudadanía, conectaban yhabilitaban el debate público, permitían el cambio social. Dehecho, en los términos de Cuello (2017), Internet posibilitó la emergencia de un nuevo lenguaje expresivo en torno a la producción creativa de prácticas políticas, códigos e imágenes desde las cuales intervenir en los modos de vida en curso. La vanguardia en la apropiación de las redes con fines activistas la tuvieron los movimientos sociales, quienes diseñaron estrategias críticas de utilización de las configuraciones de la comunicación en red propuestas por las nuevas tecnologías. En los últimos años, sin embargo, esta promesa democratizadora es puesta en tela de juicio por distintas y múltiples voces. Se critica, por ejemplo, el carácter crispado de las discusiones que se habilitan en Facebook o Twitter, la adicción generada principalmente en la juventud por los teléfonos inteligentes y la circulación de noticias falsas en las redes, con importantes efectos en la política ${ }^{3}$.

Con la intención de avanzar en la comprensión de las prácticas que, a partir del uso de redes sociales, habilitan la configuración de públicos alrededor del problema de la inseguridad, indagamos sobre diversas experiencias. En primer lugar, analizamos prácticas y contenidos emergentes de tres espacios en redes sociales vinculados a casos de inseguridad: un grupo abierto de Facebookcreado por usuarios y usuarias luego de un violento asalto sufrido en 2010 por una mujer, en la ciudad de La Plata (particularmente los 1160 posteos producidos entre el 30 de julio y el 30 de agosto de 2010 en el grupo "Carolina Píparo e Isidro") y una página de Facebook y un canal de YouTube creados y gestionados porfamiliares de un policía asesinado en 2007 también en la ciudad de La Plata ${ }^{4}$.

2 Véase Informe Global Digital Statshot Q3 201.

3 De hecho, por citar el ejemplo más sobresaliente, durante 2017 Facebook debió brindar explicaciones en el Congreso estadounidense por la proliferación de noticias falsas, producidas supuestamente a partir de interferencias de agentes rusos, que al haber sido vistas por decenas de millones de personas habrían influido en los resultados de las elecciones presidenciales de ese año. Sobre el caso: véase Timberg \& Dwoskin, 2017.

4 Sehace referencia a la página de Facebook “Justicia por las tres víctimas del triple crimen dela Planta Transmisora” y al canal de YouTube personal de una de las víctimas. 
En segundo lugar, realizamos seis entrevistas en profundidad con quienes administran diversas páginas (o fanpages) y grupos abiertos de Facebook vinculados a la experiencia de la victimización y la inseguridad ${ }^{5}$. Finalmente, participamos de acciones colectivas callejeras vinculadas a la organización y demanda de estos grupos virtuales, particularmente en una marcha por seguridad realizada en 2016, en la ciudad de Buenos Aires, bajo el lema "para que no te pase", y en tres manifestaciones de familiares de policías "caídos" que reclamaban justicia y seguridad, realizadas entre 2015 y 2017, en las ciudades de Buenos Aires y La Plata.

El material, cabe destacar, proviene de la confluencia de diversas líneas de investigación interesadas en la construcción de públicos para el delito, la configuración (pública) del problema público de la inseguridad y las dimensiones del activismo policial ${ }^{6}$. En el presente trabajo, antes que en el contenido producido y circulado en las redes, centramos nuestro interés en las dinámicas de los procesos que confluyen en estas experiencias y en las prácticas de los actores que les dan entidad, sobre los cuales realizamos un análisis de tipo cualitativo.

El trabajo se encuentra dividido en diversos apartados. En el primero, presentamos las reflexiones teórico-metodológicas sobre la relación entre espacio público y redes sociales, en la cual sustentamos nuestro análisis. En el segundo apartado, analizamos dinámicas de "grupos abiertos" de Facebook, tanto desde un análisis de emergentes de una experiencia concreta como desde "la cocina" de quienes se encargan de la administración de este tipo particular de espacios virtuales. En el tercer lugar, damos cuenta de dinámicas que incluyen el uso de redes sociales en lo concerniente a su articulación con la acción colectiva de carácter callejero (u offline). En el cuarto apartado, reparamos en las posibilidades de promoción ofrecidas por las redes sociales a través de las fanpages, así como en las prácticas y desafíos a los cuales se enfrenta la administración de estos espacios virtuales. En quinto lugar, nos detenemos en la relación entre las redes sociales y la producción de contenidos, tanto en lo referido a los usos manifestados por periodistas de policiales frente a casos de inseguridad como en lo que hace a las posibilidades de difusión por parte de los y las activistas. Por último, compartimos algunas consideraciones finales.

Entendemos que un planteo de este tipo, que repara en objetos empíricos tan diversos, permite transitar diferentes dimensiones involucradas en la me-

5 Entre ellas: "Inseguridad en Castelar", "Familiares de policías y penitenciarios", "Acá estamos las madres de Pañuelos Azules", "Vecinos alerta x inseguridad", "Azules por siempre" y "Justicia por los tres víctimas del triple crimen de la planta transmisora".

6 El artículo reúne hallazgos de tres líneas de investigación desarrolladas, en paralelo, por Galar y Focás; en las cuales se analizan el procesamiento público del problema de la inseguridad reparando en las interpretaciones y las acciones de diversos públicos relacionados en torno al tema. Una línea es desarrollada por Focás (2016), en la cual analiza las relaciones entre las percepciones del delito, los medios de comunicación yla vida cotidiana, y otras dos líneas son desarrolladas por Galar, quien indaga, por un lado, la construcción del problema de la inseguridad en diferentes provincias argentinas a partir de la ocurrencia de casos policiales que conmocionaron a la opinión pública (2017a); y, por otro lado, se detienen en la constitución de públicos alrededor de demandas de grupos policiales en la zona metropolitana de Buenos Aires (2017b). 
diatización delo público político en relación con las redes sociales: ellugar delas redes sociales en Internet en la configuración de la esfera pública contemporánea, las posibilidades de comunicación para públicos y activistas, las tensiones entre lo privado y lo íntimo con lo público y lo publicitado y, finalmente, diversos vínculos entrelo sucedido en las redes socialesyla participación ciudadana.

\section{ESPACIO PÚBLICO Y REDES SOCIALES}

En el presente análisis, en términos teóricos y metodológicos, apelamos a una definición amplia de espacio público, alineada con desarrollos de la sociología de los problemas públicos. Más concretamente, siguiendo a François y Neveu (1999), referimos como espacio público al punto de intersección entre diversos campos sociales comprendido por acciones realizadas con el objetivo de "ser vistas y oídas". Entendido en estos términos, el carácter público de un acontecimiento ingresa en el registro de la acción pública, concebida como toda experiencia realizada para "ser vista y oída", que moviliza referencias al bien común y es conformada por una serie de arenas (públicas), en las cuales interactúan actores, instituciones y prácticas (Schillagi, 2011).Estas interacciones, las cuales exploramos en registros discursivos y prácticos, se constituyen en un ámbito eminentemente conflictivo. Por lo demás, en sintonía con los planteos de corte pragmatista, entendemos a lo público como un concepto empíricamente fundado en tanto la mirada está enfocada en la constitución y la emergencia de los públicos, que se encuentran en una dinámica de composición constante.

Frente a esta concepción, destacamos la práctica de la intervención como unidad mínima de participación de los usuarios y las usuarias en redes sociales que dinamizan esta configuración de lo público. En este sentido, las redes sociales exigen la acción de intervenir como unidad mínima de participación: hacerse miembro de un grupo de Facebook, twittear sobre un tema, subir una foto a Instagram, respaldar una petición en Change.org, comentar un posteo. De esta manera, una cuestión interesante involucrada en la participación en redes sociales es, desde nuestra perspectiva, la inclusión delas dos dimensiones que otorgan al público Cefaï y Pasquier (2003). Estos autores entienden al público, por un lado, como una audiencia mediática y, por otro, como un colectivo de ciudadanos preocupados por un tema. El público en las redes sociales es un público que, en diversos grados, ejerce por definición la acción de participar.

Las implicancias metodológicas de esta concepción de público en redes sociales son notables. Siguiendo a López y Ciuffoli (2012), en Facebook, lo que es extensible al resto de las redes sociales, "usar" es sinónimo de publicar. Usuarios y usuarias "postean" (o comparten con sus "amigos") enlaces de noticias, fotos, videos y opiniones. Estos posteos dejan en las redes sociales rastros que permanecen como huellas que se organizan de manera cronológica inversa. 
Esta configuración de las redes enfrenta -durante el análisis-a la dificultad de sistematizar y categorizar una cantidad incalculable de discursos, introducidos en lenguajes que evidencian marcas de la oralidad. Sin embargo, cabe destacar que esta complejidad de la fuente se equilibra con una ventaja evidente: que todo quede registrado. La participación implica intervención y facilita el acceso a fuentes completas y muy ricas en material empírico.

Otra implicancia metodológica es planteada por Hine (2012), quien en su análisis propone considerar a las redes sociales como espacios de interacción social. La implicancia metodológica de esta concepción es la imposibilidad de captar las acciones desarrolladas en redes sociales dentro de un marco interpretativo que reproduzca aquellas divisiones que, justamente, se disuelven en su accionar. Una de estas divisiones que los usuarios y las usuarias vencen constantemente, talvezla más importante, es aquella diferencia entre el mundo online y el offline, entre la dimensión real y la virtual. En esta dirección, Lópezy Ciuffoli (2012) enfatizan que, pese al sesgo instalado en gran cantidad de analistas, la virtualidad no constituye un mundo falso o imaginario. Por el contrario, la virtualización es la propia dinámica del mundo común, aquello por lo que compartimos una realidad. En definitiva, lo virtual, lejos de delimitar el reino de la mentira, es precisamente un modo de existencia donde emerge tanto lo verdadero como lo falso.

\section{HACERSE MIEMBRO}

En agosto de 2010 una joven empleada pública embarazada, Carolina Píparo, acababa de retirar dinero de un banco en la ciudad de La Plata, capital de la provincia de Buenos Aires, cuando fue asaltada por un grupo de delincuentes. La mujer fue herida con arma de fuego, producto de lo cual su hijo, a quien llamaron Isidro, murió pocos días después. El caso, sobre el cual se realizó una intensa cobertura por parte de los medios de comunicación, se nacionalizó rápidamente. Alrededor del caso Píparo se movilizaron públicos a través de la realización de protestas por las calles de La Plata y se conformaron grupos en las redes sociales. Acompañando al despliegue del caso, las familias de las víctimas intervinieron públicamente en debates sobre la situación de seguridad, la responsabilidad política sobre el problema y la efectividad de la justicia.

El análisis del grupo abierto de Facebook "Carolina Píparo e Isidro", uno de los más relevantes conformados al calor del caso por la cantidad de participantes y la legitimidad otorgada por la participación en él de familiares de las víctimas, permite acceder a dinámicas que se producen en estos espacios virtuales. El grupo fue abierto por un usuario el mismo día del asalto con el objetivo de que "todos nos unamos para q carolina piparo e Isidro q estan peleando por sus vidas se mejoren y puedan salir adelante q es lo q todos queremos..." (“Carolina Píparo e Isidro”, Facebook, 2010). En este sentido, siguiendo 
a López y Ciuffoli (2012), la idea de "grupos" fue incorporada por Facebook como contraposición a los foros de discusión que son fomentados por otras plataformas virtuales, como los diarios en sus ediciones online. La red social se propuso correr del primer plano el debate, la disertación y el poder de la palabra para ubicar allí la pertenencia. La metáfora grupal, explicitada en la descripción del grupo en la frase "que todos nos unamos", plantea la participación como un paso posterior a la identidad común. En la actualidad, como expresamos en la introducción, una de las críticas a las redes sociales es que el fomento de identidades grupales, posibilitada por complejos algoritmos, favorece la generación de homogeneidades ideológicas que luego, al encontrarse con grupos antagonistas, colisionan.

Un elemento emergente que se desprende del análisis es la convivencia de un elenco estable con intervención diaria, un grupo más numeroso con participación ocasional y un tercer grupo, más vasto aun, que limita su aporte a la aprobación tácita incluida en el ser miembro. La diferenciación de estos tipos de participantes en el debate, por sencilla que parezca, resulta particularmente interesante en tanto entra en tensión con una de las imágenes más difundidas por los optimistas de las redes sociales. En los términos de Sorj y Fausto (2016), en este sentido, la nueva figura social de los movimientos promovidos en Internet suele ser la de los colectivos que enfatizan el carácter democrático y fluido, donde no existirían líderes ni jerarquías. Esta horizontalidad, de hecho, no se confirma en la práctica del grupo analizado.

El análisis también deja entrever que la forma en la cual se despliega la discusión en el grupo se vincula a la importancia otorgada por sus miembros a ciertos hechos con difusión pública sobre el caso. En otros términos, ciertos eventos, generalmente difundidos a través de los medios de comunicación, ameritan las intervenciones de los miembros y dinamizan el intercambio. En el marco del caso en cuestión los miembros intervienen, por ejemplo, a colación de la difusión de un parte médico sobre el estado de salud de Píparo, a partir de ciertas declaraciones del gobernador ${ }^{7}$ sobre el caso que suscitaron polémica y al conocerse la muerte del hijo de la mujer, pocos días después del asalto. Este último evento, desde una mirada más general, marca además un quiebre en el tono de las intervenciones de los miembros.

En la primera etapa, con Píparo y su hijo internados en un hospital, gravemente heridos, el interés de la participación estuvo centrado en apelaciones a la fe y en la solidaridad emocional con asiento en procesos de identificación con las víctimas ${ }^{8}$. En la segunda etapa, inaugurada con la muerte del hijo de Píparo,

7 Daniel Scioli, gobernador de la provincia de Buenos Aires, Argentina, en dos períodos consecutivos entre el 10 de diciembre de 2007 y el 10 de diciembre de 2015.

8 La identificación con las víctimas por parte de los usuarios y las usuarias se asentaba en distintas bases: analogías con historias personales sobre la maternidad (madres/padres que perdieron embarazos, que sufrieron la muerte de hijos recién nacidos o cuyos hijos nacieron con dificultades), analogías con historias personales sobre el delito (familiares de víctimas o víctimas de hechos violentos), analogías con la familia Píparo desde su construcción como familia tipo y su pertenencia a la comunidad de ciudadanos (de bien). 
los miembros del grupo priorizaron la búsqueda de responsables y la demanda de justicia. De esta manera, la discusión en el grupo se motoriza a través de temas que, por lo general, ingresan al espacio público por otras vías antes de ser retomados en la dimensión virtual. El análisis permite asimismo observar etapas de la discusión, donde las intervenciones de los usuarios y las usuarias se orientan a objetivos diferentes, como se observa en el pasaje de la demostración de solidaridad hacia la búsqueda de responsables y la exigencia de justicia. Por lo demás, en esta dimensión virtual de la experiencia pública prevalecen lecturas de corte emocional que se vinculan a las formas en que son construidas las víctimas, victimarios y formas de matar/morir. En todo caso, en coincidencia con lo planteado en el análisis del grupo de Facebook "Resistiendo con aguante", realizado por Ferraudi Curto y otros autores (2017), más que un mero medio o superficie de inscripción de discursos, las redes sociales habilitan a través de sus dispositivos procesos de reconfiguración de subjetividades políticas. Más allá de la identidad que constituye el punto de partida, existe, desde nuestra perspectiva, cierto margen para la construcción (reconstrucción o deconstrucción) de estas identidades.

La entrevista con administradores de un grupo abierto en Facebook posibilita la incorporación al análisis de elementos vinculados a "la cocina" de esta particular forma de sociabilidad grupal. El grupo en cuestión, denominado "Inseguridad en Castelar", funciona desde 2013 y cuenta con 1493 miembros. En términos generales, el grupo reúne las demandas de inseguridad de los habitantes de Castelar, una ciudad del oeste del Gran Buenos Aires. Entre los constantes posteos, por ejemplo, Viviana, una vecina de la zona, compartió:

Vecinos. Intentaron entrarme a robar, me barretearon la puerta. Vivo en Martín Irigoyen y Bogado, Castelar Sur. 2 hombres en Gol Rojo con patente JGE 498. Ya robaron enfrente hace poco. A la vuelta robaron unas herramientas a obreros, un Gol Rojo. Hay que estar atentos ("Inseguridad en Castelar", Facebook, 12 de diciembre de 2017).

Viviana, como se observa, apela a una identidad generaly difundida, aquella que Calzado (2015) denominó "ciudadanos-víctimas", pero lo hace en el marco de un grupo particular. La intervención de Viviana, por estar publicada, evidencia que pasó los filtros dispuestos en la práctica por los administradores de la página.Segúnlosadministradores, existen “pautas en común”, comono publicar o entablar discusiones políticas y/o partidarias entre los miembros o compartir "publicidades de cualquier tipo". Esteban, uno de los administradores, afirmó durante una entrevista que "primero la información debe ser filtrada y aprobada desde la administración, ya que legalmente somos responsables por lo que se publica”. La práctica de la administración, de hecho, incluye rutinas diarias de eliminación de publicaciones que no cumplen con las "pautas en común", 
"bloqueo de miembros infiltrados" que "tienen perfiles falsos", que "tienden a generar una discusión política” y/o "utilizan el sitio para promover candidatos o sus negocios particulares". Más allá de las normas específicas de este grupo, lo destacable es la existencia misma dela norma. Si usar es participar, en el marco de los grupos abiertos la participación es formateada tanto por la estandarización de las acciones que permite la plataforma virtual como por la acción sostenida por administradores, moderadores y usuarios.

Porlo demás, finalmente, resulta interesante destacar interacciones que desde la administración se producen tanto con el mundo online como con el offline. Por un lado, resulta evidente la retroalimentación de esta página con otros "grupos", "páginas" y "eventos" con los cuales se comparten principios ideológicos y objetivos concretos. Estos vínculos deben ser "aprobados", al tiempo que en ocasiones son promovidos desde la administración del grupo. Por otro lado, se manifiesta una constante interacción con el mundo offline, en especial de parte de los administradores que mantienen reuniones periódicas con dirigentes políticos, funcionarios policiales y del poder judicial que los informan "sobre la situación del municipio en materia de inseguridad". En palabras del entrevistado, quienes comenzaron el grupo "somos vecinos del partido de Morón, muchos de nosotros, víctimas ofamiliares asesinados porla delincuencia que nos fuimos conociendo en reuniones y marchas que se realizaban pidiendo seguridad en los barrios". Esta interacción se mantiene en paralelo al desarrollo del grupo virtual y, simultáneamente, incorpora otros actores, con quienes comparten fines prácticos y orientación ideológica.

\section{SALIR A LA CALLE}

El análisis del grupo abierto a colación del caso Píparo, al cual hicimos referencia en el apartado anterior, permite dar cuenta de dinámicas que incluyen la acción colectiva de carácter callejero. Referimos específicamente al ejercicio de reparar en articulaciones de la dimensión virtual con la acción colectiva offline, que además posibilita incorporar al análisis la variable temporal y espacial.

En el despliegue del grupo de Facebook, al calor del caso, se discuten las convocatorias a las manifestaciones públicas que serán realizadas para pedir justicia y seguridad. Es común observar el intercambio de opiniones sobre los lugares, días y horarios en los cuales reclamar, más allá del efectivo control que los miembros puedan ejercer sobre estas variables. En agosto de 2010, una vez conocida la muerte del hijo de Píparo, un grupo de vecinos realizó un "cacerolazo" en la plaza central de La Plata, en reclamo de "justicia y seguridad". La manifestación había sido organizada vía Facebook por usuarios y usuarias que, desde ese momento, en su accionar en el espacio público callejero, comenza- 
ron a presentarse públicamente como "autoconvocados". De esta manera se evidencia en el caso la imbricación de los sujetos políticos en la articulación online y offline.

Por otro lado, durante las acciones colectivas callejeras, los usuarios y las usuarias intervenían en el grupo de Facebook a través de opiniones sobre el desarrollo de las manifestaciones, valiéndose de lo que observaban en los medios de comunicación, televisivos o virtuales, que las cubrían. En esta práctica queda de manifiesto el carácter espacialmente descentralizado del grupo; en el cual, por tratarse de un caso nacionalizado por los medios de comunicación, participaban personas de diferentes provincias y que, por la distancia, se veían impedidos de participar en la acción colectiva callejera. En la actualidad, cabe destacar, el avance tecnológico de los celulares inteligentes y las redes de telefonía $4 \mathrm{G}$ permiten que los participantes de las acciones callejeras puedan subir contenido en tiempo real sobre lo que viven, y que quienes usan las redes sociales "compartan" el material con miras a difundir las iniciativas. De este modo dinamizan más esta sinergia.

Sin embargo, en términos prácticos, las redes sociales permiten en algunas ocasiones a los usuarios y usuarias entrar en contacto, interactuar, conocerse y, a través de estas operaciones, realizar un pasaje hacia un compromiso más activo, tanto individual como colectivo, con posibles repercusiones en el mundo offline y en el online. Edith, familiar de un policía asesinado en 2012, comentó durante una entrevista que su ingreso a los colectivos de víctimas tuvo su origen en las redes sociales: "Fue por Facebook, contactando así diferentes asociaciones de víctimas, tratábamos de unirnos por Facebook y después juntarnos". Según las personas entrevistadas, el contacto a través de redes sociales, el pertenecer a los mismos grupos, el "comentar" en las mismas páginas o "hacerse amigos" habilita un contacto posterior que se produce generalmente a través de los canales privados que también ofrecen las redes sociales. Son los "mensajes privados" o los "grupos de WhatsApp" (una aplicación de mensajería instantánea que para algunos funciona como red social) donde se fortalecen lazos y se promueven iniciativas que, en ocasiones, vuelven al espacio público. Las redes sociales son utilizadas como instrumentos de coordinación: como mecanismos para articular acciones colectivas en el espacio público virtual y no virtual.

Finalmente, en los momentos posteriores a las manifestaciones, se distinguen en el grupo evaluaciones de estas iniciativas, particularmente diagnósticos que buscan explicaciones a una convocatoria que, en comparación con la masiva "conmoción en las redes sociales", suele resultar escasa. Esta percepción o falta de acompañamiento genera usualmente enojo y diversas lecturas; por

9 La convocatoria que circulaba (y se discutía) por Facebook expresaba: "CONVOCATORIA: DÍA DEL NIÑO (DOMINGO 8 DE AGOSTO 2010 A LAS 18 HS.) en las principales plazas de nuestro lugar de residencia MARCHA pacifica y familiar para pedir mayor seguridad y por los derechos q no tubo Isidro al nacer y los de todos los ciudadanos!!! en La Plata plaza moreno! los esperamos, debemos comprometernos juntos podemos mas!! [sic]!" (“Carolina Píparo e Isidro", Facebook, 8 de agosto de 2010). 
ejemplo, el uso de metáforas que piensan a la sociedad "dormida” o que está “anestesiada”. Las redes sociales, según nuestra interpretación, funcionan en el caso como una caja de resonancia que posibilitó una participación masiva al permitir la deslocalización (o lejanía con los hechos) de los usuarios y las usuarias, y un compromiso que puede limitarse a la mera expresión, aquella "catarsis inconducente" denunciada por los críticos de las redes sociales que Sorj denomina como "ilusión del click-activismo" (Sorj y Fausto, 2016, p. 9).

Cabe destacar que este aparente desacople entre la conmoción en las redes sociales y la inferencia en la acción pública callejera también emerge en la calle. En octubre de 2016 participamos de una manifestación frente al Congreso Nacional organizada por un grupo de familiares de víctimas bajo el lema "para que no te pase". La manifestación pretendía ser una secuela de la masiva concentración convocada por Juan Carlos Blumberg en 2004, pero la convocatoria, estimada en unas 5 a 7 mil personas, quedó muy lejos de las 150 a 200 mil que se calculó que participaron una década atrás. "Es una tristeza que haya tan poca gente, pero es así, hasta que no te pasa no te das cuenta”, comentó una farmacéutica de Tigre, cuyo hijo murió luego de una golpiza a la salida de un boliche ${ }^{\mathbf{1 0}}$. La mujer sostenía un cartel impreso en hoja A4 que decía "no quiero seguir perdiendo familiares" (véase Focás \& Galar, 2016). De esta manera, el público constituido en Facebook puede ser considerado masivo al punto de ser convertido por los medios de comunicación en hecho noticiable, sin que se evidencie una correspondencia o medie un paso necesario por la movilización en las calles.

Es decir, no toda propuesta de movilización online deviene linealmente en su puesta en escena en el mundo offline. Por caso, para Esteban, administrador del grupo "Inseguridad en Castelar" al cual antes hicimos referencia, es evidente la brecha existente entre la participación en el mundo online y en la dimensión offline, al punto que progresivamente el grupo (o, más concretamente, los administradores) decidió actuar solo en términos virtuales. En palabras de Esteban:

En un principio convocamos marchas, algunas fueron de gran caudal de vecinos y otras no tanto. Aunque ya desistimos de organizar otras, debido al desgaste que produce, el poco compromiso de los vecinos y la dificultad de equiparar criterios. Los encuentros se realizan entre los administradores y con vecinos casualmente en la calle cuando nos reconocen y nos paran para preguntarnos algo. Seguimos la actividad solamente desde la red" (Entrevista a Esteban, administrador del grupo "Inseguridad en Castelar", febrero 2017)

Es decir, en estos nuevos espacios adquieren visibilidad y se "viralizan" opiniones concebidas en la vida online y offline, pero que no necesariamente derivan en movilizaciones callejeras.

10 Uso coloquial en Argentina. Hace referencia a una discoteca o a un sitio nocturno donde se puede comer, beber y bailar. 


\section{ADMINISTRAR UNA PÁGINA}

"Administrar" una página de Facebook, a las que la empresa denomina fanpages, o una cuenta de Twitter, o un canal de YouTube, implica desarrollar procesos de selección, edición y de producción de textos e imágenes. El ejercicio de administrar cuentas, retomando los planteos de van Dijck (2016), se vincula con la apelación a las redes por parte de los actores con miras a la autopromoción. En este sentido, las redes sociales no se constituyen solo como plataformas para la participación personal, sino también como herramientas para la promoción de los usuarios y las usuarias, y para las causas en las cuales se involucran. En las redes sociales se borra la distinción entre la expresión personal y la publicidad, se produce una mercantilización de la identidad propia como un bien que hay que vender y consumir. Las posibilidades de promoción ofrecidas por las redes sociales son explotadas por los actores interesados en la demanda de justicia y seguridad, ya sea en los términos de casos concretos como de concepciones más amplias sobre el problema.

Rosa, familiar de un policía asesinado en 2007 en La Plata, administra una página de Facebook denominada "Justicia para las tres víctimas del triple crimen de la planta transmisora". La fanpage fue abierta en 2010 y cuenta con alrededor de mil seguidores. La página funciona como un canal de expresión de los familiares de este policía asesinado, en el cual la "ideología del compartir" se manifiesta en el "posteo" de notas periodísticas; que usualmente son acompañadas por valoraciones de aprobación o desaprobación de los hechos a los cuales refieren. Rosa también "comparte" convocatorias a eventos vinculados al caso, como misas en recuerdo de las víctimas o manifestaciones en demanda de justicia. Esta familiar de víctima usualmente comparte imágenes religiosas, fotografías de las víctimas y de las acciones colectivas emprendidas por miembros de la familia, siendo una continuidad el aura religiosa ligada al culto católico que practica. La administradora, finalmente, postea referencias a otros casos policiales y temas asociados al crimen.

Rosa administra, asimismo, un canal de YouTube, una red social que en sus comienzos, hace más de una década, pretendía convertirse en un archivo colectivo de producciones amateurs para luego fusionarse con grandes empresas del entretenimiento y perder ese carácter inicial, transformando a usuarios y usuarias en televidentes (van Dijck, 2016). La administradora utiliza YouTube en un sentido intermedio, "subiendo" producciones propias, también seleccionando y compartiendo material audiovisual realizado por medios de comunicación en torno al caso, siempre con miras a mantener visible el asesinato de su cuñado. Se trata entonces de meta-ediciones, piezas que contienen varias ediciones y selecciones. La mayoría son segmentos de noticieros que fueron captados filmando a un televisor, también producciones propias y logradas con editores simples de video; básicamente, son cortos caseros de poca calidad o seguidillas 
de fotos sobre iniciativas de los familiares. Los videos que Rosa "sube" a YouTube, finalmente, son ingresados por ella misma al circuito de Facebook, cuando los comparte a través de la fanpage que gestiona.

De las entrevistas realizadas recientemente con administradores de páginas en Facebook, resultan interesantes dos elementos emergentes que, entendemos, refieren a una nueva etapa de esta red social. Por un lado, referimos a la masividad que adquirió la red social, no sólo por cantidad de usuarios y usuarias que la utilizan, sino también por la cantidad de iniciativas que los mismos sostienen en este espacio virtual ${ }^{11}$. Edith, familiar de un policía federal asesinado en 2010 en La Plata, comentó durante un encuentro que es administradora de varias páginas interrelacionadas y que comparte esta tarea con otras familiares de víctimas de la delincuencia. En este sentido, la gestión de una página puede ser un ejercicio colectivo, lo que obliga a negociar tácita o explícitamente los criterios de la administración.

Más interesante aun, por otro lado, son los procedimientos que estos administradores debieron adoptar debido a la proliferación de la circulación de noticias falsas en las redes sociales. La circulación de fake news, tal como se conoce este fenómeno en inglés, constituye la base de una de las críticas más extendidas a las redes sociales en la actualidad. Pero, al mismo tiempo, evidencia en un caso extremo las vinculaciones existentes entre el mundo offline y online, la forma en que las estructuras de poder permean las redes, corroyendo su potencial democratizador. En este sentido, para Sorj y Fausto (2016) el fenómeno de las fake news manifiesta la posibilidad de intervención del mundo offline en las redes sociales, pues logra incluso apropiarse de los movimientos de opinión y movilización que el mundo virtual promueve. Edith, administradora de una de las páginas que analizamos, contó que en un principio "donde aparecía la noticia, la primera que estaba la ponía". Estas noticias, generalmente vinculadas a casos de inseguridad, suelen llegar a las administradoras por diversas vías, incluyendo los medios de comunicación convencionales o los datos proporcionados por informantes, ya sean fans de la página o externos a la red social. Sin embargo, según Edith, "ahora es más cerrado" en tanto las administradoras no "postean" información "hasta verificar que la noticia sea cierta".

Por lo demás, administrar una página implica también estar disponible para responder a las personas que, con diferentes fines, se ponen en contacto con los administradores. En general, en el caso de los familiares de víctimas de la inseguridad, suelen ser otras víctimas con dudas sobre procedimientos legales o administrativos en el marco del procesamiento judicial de sus casos. Elba dice "hablar con la gente" en la página que administra, que cuenta con más

11 Cabe destacar que se trata de una masividad que es acompañada por una migración del público más joven hacia otras redes sociales, como Instagram o Snapchat. Según el informe de la consultora internacional eMarketer, esta migración se está produciendo además en términos acelerados (eMarketer editor, 12 de febrero de 2018). 
de treinta mil fans, y "al que se le puede solucionar el problema se le soluciona". Además, suelen contactarse periodistas interesados en aclarar dudas sobre alguna acción colectiva convocada desde la página o sobre alguna información socializada por la página a partir de los datos aportados por los usuarios y las usuarias.

El administrador de la página de Facebook "Vecinos Alerta x Inseguridad", la cual cuenta con más de 16 mil "me gusta”, permite pensar otra característica del ejercicio de gestionar una página. Los administradores de esta página, dedicada a denunciar el aumento de la inseguridad en la zona de Lomas de Zamora, Lanús, y Quilmes, realizan la gestión en términos anónimos. En este caso, debido a la sensibilidad de la información que manejan, por la cual aseguran haber sufrido persecuciones y amenazas, los administradores prefieren el anonimato. "El grupo nació por el aumento de la inseguridad en la zona. Venta de drogas, policía corrupta, no podíamos denunciar con nombre y apellido, entonces surgió la idea de la página", indicó uno de ellos en una entrevista. El sostenimiento del anonimato influye en otras características vinculadas a la dinámica de la página, por ejemplo: prefieren manejarse por “mensaje privado". Según uno de los entrevistados, "Nos manejamos mucho por privado, nos cuentan lo que pasa y desde la página armamos como un mapa del delito, zonas inseguras y también escrachamos a políticos y policías corruptos". Además evitan convocar a marchas o manifestaciones, aunque sí acompañan y difunden iniciativas de otros grupos con los que poseen afinidad ideológica. "Rara vez convocamos a marchas nosotros, sí acompañamos a otros grupos que las quieren hacer", dice otro de los entrevistados. La recepción de denuncias anónimas, en sintonía con lo que afirmábamos antes en la experiencia de otros grupos, profundiza la necesidad de chequear los datos: "se cuenta todo lo que podemos confirmar que es real".

\section{PRODUCIR CONTENIDOS}

Los medios de comunicación retoman asiduamente aquello que circula en las redes sociales, más allá de la voluntad de quienes administran las páginas o de los usuarios y las usuarias, convirtiéndolas en fuente de información. Frente a un caso de inseguridad, los periodistas acceden con rapidez y facilidad a imágenes cotidianas y pensamientos íntimos de las víctimas, así como a información que transforman en pistas para dilucidar los casos policiales junto con sus audiencias. El acceso a los perfiles de Facebook de las víctimas, a las imágenes de su cotidianeidad y a su mundo íntimo, se volvió un recurso ineludible para la cobertura de casos policiales (Focás \& Galar, 2016).

Algunos periodistas que entrevistamos para trabajos previos (Focás, 2016; Focás \& Galar, 2016), reconocen que, como parte de su rutina cotidiana, utilizan las redes sociales para acceder tanto a datos de las víctimas 
como de los victimarios. En Facebook, por ejemplo, los periodistas pueden adquirir fotografías de las víctimas, así como acceden a información sobre sus preferencias, costumbres y "amigos" del entorno virtual. También los familiares de las víctimas, en general cuando las víctimas son mujeres que desaparecen de sus entornos y se sospecha que fueron secuestradas, utilizan esta red social para hacer extensiva la búsqueda, tal como sucedió con los resonantes casos de Candela Rodríguez, Ángeles Rawson y Lola Chomnalez ${ }^{12}$. Recurrir al uso de la información pública disponible en Internet agiliza el trabajo periodístico, también lleva muchas veces a una difusión irresponsable de ciertos datos, especialmente en el momento de las búsquedas de las víctimas.

Los motivos de este uso asiduo por parte de los medios de comunicación son diversos, entre los cuales podemos destacar la propia circularidad de su dinámica, la falta de recursos en una producción de noticias que se precariza y la creciente competencia entre plataformas. Incluso, en algunas oportunidades, el uso mismo de las redes sociales se vuelve hecho noticiable en sí mismo, cuando los medios de comunicación retoman la dinámica delas redes como indicador de conmoción social, plasmándolo en titulares como "se multiplica el apoyo en Facebook" o "Crece el apoyo a las víctimas en las redes sociales". En este sentido, en sintonía con lo planteado por Raimondo Alselmino y otros actores (2015), la disposición del material circulante en las redes sociales presenta renovados dilemas éticos para la práctica periodística en el contexto de una imbricación cada vez más compleja de los espacios público, privado e íntimo.

Más interesante aun es que las redes sociales se hayan constituido en un importante canal para la difusión de información para los grupos de activistas, y particularmente para los familiares de víctimas que pretenden publicitar y hacer conocer lo sucedido. Utilizan este medio para difundir convocatorias a las acciones colectivas que organizan, como manifestaciones y homenajes. Además, circulan cartas públicas, una forma de intervención que trasciende la dimensión virtual en tanto también suelen ser difundidas mediante el envío a los medios de comunicación. Se trata de textos en los cuales familiares y allegados expresan sentimientos en primera persona dirigidos a las autoridades, a

12 Candela Sol Rodríguez Labrador fue secuestrada el 22 de agosto de 2011, cerca de su casa en Hurlingham, provincia de Buenos Aires, Argentina. Luego de una intensa búsqueda fue hallada muerta nueve días después con signos de asfixia. Su madre, Carola, antes pidió por su liberación en todos los medios de comunicación y el tema acaparó la atención pública durante varias semanas.

Ángeles Rawson desapareció el 10 de junio de 2013. Al día siguiente fue hallada muerta en un predio de la Coordinación Ecológica Área Metropolitana Sociedad del Estado (CEAMSE), en la localidad bonaerense de José León Suárez. Tenía 16 años y vivía en el barrio de Palermo, en la ciudad Autónoma de Buenos Aires. Las noticias sobre Ángeles fueron tema de agenda durante meses. El portero del edificio fue finalmente encontrado autor de crimen.

Lola Chomnalez tenía 15 años cuando apareció muerta en Uruguay, el 28 de diciembre de 2014, donde pasaba unas vacaciones junto a su madrina. Tenía un puntazo en un brazo, un golpe en la cabeza y marcas de asfixia. El caso continúa en etapa de investigación, sin ser resuelto. 
la opinión pública e, incluso, a sus seres queridos fallecidos. Las cartas suelen ser difundidas en ocasiones consideradas significativas, como cumpleaños de las víctimas o aniversarios de los crímenes, para desmentir trascendidos o solicitar celeridad a la justicia. Las redes son utilizadas, además, para la difusión de comunicaciones sobre acontecimientos vinculados a la causa judicial o a la demanda por seguridad, y constituyen un recurso privilegiado para la difusión de información principalmente cuandolos casos pierden visibilidad en la agenda pública y mediática. En este sentido, retomando a Cuello (2017), a partir del uso de redes sociales los activistas proponen no solo formas alternativas de comunicación, sino también, en ocasiones, particularmente cuando la atención mediática es limitada, rupturas concretas a los cercos de la comunicación hegemónica.

\section{CONSIDERACIONES FINALES}

A lo largo del artículo esbozamos algunas de las principales dimensiones que se establecen entre la configuración pública del problema de la inseguridad y el uso de redes sociales. Algunos hallazgos presentes en este artículo permiten aventurar que las redes sociales funcionan como un grupo de cohesión e identidad, que en el caso de la inseguridad refuerza un sentimiento de vulnerabilidad compartida. Tanto en el rol de administradores como de usuarios o usuarias, los sujetos entran en contacto, interactúan, se conocen y establecen vínculos en torno a la prevención del delito, es decir, implementan estrategias colectivas para evitar ser víctimas de la inseguridad. De este modo, en un primer momento, analizamos las implicancias de "hacerse miembro" de un grupo de Facebook, mostramos cómo los integrantes de los grupos comparten sus experiencias vinculadas con la inseguridad, para lograr una identidad común. Existe, como vimos, una evidente retroalimentación de las páginas que analizamos con otros "grupos", "páginas" y "eventos" con los cuales sus administradores comparten principios ideológicos y objetivos prácticos. Estos vínculos, en tanto deben ser aprobados por el filtro de la administración, aparecen legitimados. En otras ocasiones son directamente promovidos desde la administración de los grupos y fanpages.

En un segundo momento, analizamos las interacciones entre el espacio virtual y el espacio de la calle. Como sostienen Sorj y Fausto (2016), un consenso actual entre los analistas de redes sociales es que las prácticas vinculadas al ciberactivismo no se encuentran disociadas de otras formas de intervención, en tanto el mundo online y el mundo offline permanecen profundamente entrelazados. En los grupos de Facebook analizados, por ejemplo, se discuten las convocatorias a las manifestaciones callejeras que serán realizadas para pedir justicia y seguridad. Algunos administradores de grupos de Facebook dan cuenta de cierta brecha entre el mundo online y el offline que expresa que, des- 
de la perspectiva de los actores, "poner el cuerpo" en la calle no se trata de una práctica tan extendida como opinar en la red social. Los mismos participantes de manifestaciones callejeras (véase Focás \& Galar, 2016) refieren con cierta frustración a una baja concurrencia que no se condice con la "conmoción" en las redes sociales. También, los administradores de grupos y páginas de Facebook dan cuenta de una brecha entre los posteos y la "presencia" en reuniones o marchas sobre el tema. Esta falta de correspondencia, como dimos cuenta, promueve que los administradores restructuren sus prácticas activistas, sus objetivos y las metas de sus proyectos. De esta manera, entendemos que existe un espacio de imbricación entre la dimensión online y offline, así como entre espacios públicos mediatizados y no mediatizados, entre actores participantes de diferentes arenas públicas.

Asimismo, el uso de las redes sociales posee diversas implicancias prácticas en el marco de las intervenciones públicas de familiares de víctimas: posibilita la conformación de colectivos interesados en el tema, uso que puede tener correlatos en la acción pública callejera; permite trascender la dimensión de lo local a partir de la integración de audiencias interpeladas en un registro nacional de lo público; conecta a usuarios con los familiares; y facilita la circulación de información que desborda lo producido por las empresas de comunicación.

Ahora bien, ¿el resultado de estas imbricaciones constituye un espacio público nuevo o renovado?, ¿qué es lo nuevo y que es lo que adquiere nuevos ropajes en la configuración de este espacio público?, ¿este fenómeno de las redes sociales, aparentemente imparable, es positivo o negativo desde el punto de vista de la democratización de la palabra y la conformación de colectivos políticos? Cabe retomar uno de los debates que planteamos al comenzar este artículo, aquel sostenido entre optimistas y pesimistas en relación al uso de las redes sociales. La versión pesimista considera que el uso de las redes sociales en Internet favoreció el empobrecimiento y la polarización de la cultura y el debate, la destrucción de la privacidad y la ilusión del click-activismo, que no modifica las estructuras reales de poder, fortalece la mentalidad de los opuestos y la trivialización de los asuntos de interés público. La versión optimista, por su parte, realza las nuevas posibilidades de comunicación horizontal, la eliminación de las distancias físicas (lo que facilita el intercambio de opiniones en una escala sin precedentes) y la disminución de la importancia relativa de los medios de comunicación. Coincidiendo nuevamente con Sorj y Fausto (2016), entendemos que ambas posiciones apuntan a fenómenos reales, y que el ciberactivismo acontece bajo la influencia de ambas tendencias.

El impacto del nuevo mundo virtual no puede ser disociado de los procesos sociales más amplios acaecidos en la sociedad civil y en el sistema político, como los procesos de individuación o el debilitamiento de los partidos polí- 
ticos, que a su vez son afectados por las nuevas formas de comunicación. La dimensión virtual del espacio público nutre, así, la configuración de una esfera pública cada vez menos unívoca y estática (Raimondo Anselmino et al., 2015). En la medida en que gran parte de la comunicación se realiza vía redes sociales, hay una nueva conformación del espacio público. Son, por ejemplo, redes sociales que en gran medida no controlan el contenido de los mensajes, pero sí definen el formato a través del cual se organiza la información, que además capturan y utilizan con fines comerciales.

El acelerado régimen de actualización de las redes sociales requiere reflexiones situadas sobre suslímites y potencialidades, sobre la amplitud de usos creativos que habilita en los modos de organización política.

\section{REFERENCIAS}

Calzado, M. (2015), Inseguros: El rol de los medios y la respuesta política frente a la violencia de Blumberg a hoy. Buenos Aires: Aguilar.

Cefaï, D. \& Pasquier, D. (2003), Lessens du public. Publicspolitiques, publics médiatiques. Paris: PUF.

Cuello, N. (2017), El lenguaje expresivo de las redes. Prácticas colectivas de imaginación política online. Sociales en debate, 12, pp. 79-86. Recuperado: 5/3/2018. En línea: http://www.sociales.uba.ar/?page_id=48297.

eMarketer Editors (february 12, 2018), Facebook Losing Younger Users. But not all are migrating to Instagram. eMarketer. Recuperado: 26/02/2018. En línea: https:// www.emarketer.com/content/facebook-losing-younger-users-at-even-fasterpace.

Ferraudi Curto, C., Pinedo, J. \& Welschinger, N. (2017), Resistiendo con aguante. Prácticas de subjetivación política en Facebook como plataforma de militancia. Prácticas de oficio, 19(1), pp. 87-100. Recuperado: 5/3/2018. En línea: http:// ides.org.ar/wp-content/uploads/2012/04/8.-FERRAUDI-CURTO-PINEDO-YWELSCHINGER.pdf.

Focás, B. (2016), La trama de la inseguridad. Percepciones del delito, medios de comunicación y vida cotidiana. Tesis doctoral en Ciencias Sociales, Universidad de Buenos Aires (UBA), Argentina. Inédita.

Focás, B. \& Galar, S. (2016), Inseguridad y medios de comunicación. Prácticas periodísticas y conformación de públicos para el delito en Argentina (2010-2015). Delitoy Sociedad,41,pp.59-76. Recuperado5/3/2018. Enlínea:http://www.scielo. org.ar/pdf/delito/v25n41/v25n41a03.pdf. 
Focás, B. \& Galar, S. (2016), Sin mano dura ni mano propia. Revista Anfibia. Recuperado: 10/02/2018. En línea: http://www.revistaanfibia.com/cronica/sin-mano-durani-mano-propia/.

François, B. \& Neveu, E. (1999), Espaces publics mosaïques. Acteurs, arènes et rhétoriques des débats publics contemporains. Rennes: Presses Universitaires de Rennes.

Galar,S.(2017a),Cuandolasangrenosecarápido. Muertesviolentascomoacontecimientos públicos. La Plata: EDULP.

Galar, S. (2017b), Policías en acción. Hacia una caracterización de la red de activistas vinculados a la institución policial en la región metropolitana. Argumentos. Revista de Crítica Social, 19, 43-63.

Hine, C. (2012), The Internet: Understanding Qualitative Research. New York: Oxford University Press.

Informe GlobalDigitalStatshotQ32017. Recuperado:01/02/2018Enlínea:https://www. slideshare.net/wearesocialsg/global-digital-statshot-q3-2017

Kessler, G. (2009), El sentimiento de inseguridad. Sociología del temor al delito. Buenos Aires: Siglo XXI Editores.

López, G. \& Ciuffoli, C. (2012), Facebook es el mensaje. Oralidad, escritura y después. Buenos Aires: La Crujía.

Raimondo Anselmino, N., Reviglio, M. C. \& Diviani, R. (2015), Esfera pública y redes sociales en internet ¿qué es lo nuevo en Facebook? Revista mediterránea de comunicación, 7, 211-229.

Schillagi, C. (2011), Problemas públicos, casos resonantes y escándalos. Algunos elementos para una discusión teórica. Polis, Revista de la Universidad Bolivariana, $10,30,245-266$.

Shearer, E. \& Gottfried, J. (September 7, 2017), News Use Across Social Media Platforms 2017. Pew Research Center. Journalism \& Media. Recuperado: 04/03/2018. En línea: http://www.journalism.org/2017/09/07/news-use-across-social-mediaplatforms-2017/

Sorj, B. \& Sorj, F. (2016), Activismo político en tiempos de internet. San Pablo: Plataforma Democrática.

Timberg, C. \& Dwoskin, E. (October 30, 2017), Russian content on Facebook, Google and Twitter reached far more users than companies first disclosed, congressional testimony says. The Washington Post. Recuperado: 03/01/2018. En línea: https:// www.washingtonpost.com/business/technology/2017/10/30/4509587e-bd8411e7-97d9-bdab5a0ab381_story.html?utm_term=.24e20a05ceca

van Dijck, J. (2016), La cultura de la conectividad. Una historia crítica de las redes sociales. Buenos Aires: Siglo XXI Editores. 
Santiago Galar es Licenciado en Sociología y doctor en Ciencias Sociales por la Universidad Nacional de La Plata (UNLP), Argentina. Fue becario de la UNLP (2009-2011) y del CONICET (2011-2018). Es investigador en el Instituto de Investigación en Humanidades y Ciencias Sociales de la UNLP y el CONICET (IdIHCS / UNLP - CONICET). Se desempeña como profesor en el Departamento de Sociología y en la Maestría en Ciencias Sociales dela Facultad de Humanidades y Ciencias dela Educación (FAHCE-UNLP). Es miembro del Núcleo de Estudios sobre Seguridad en la provincia de Buenos Aires, UNLP, y del Grupo de Estudios sobre Policía y Fuerzas de Seguridad del Instituto de Desarrollo Económico y Social, Universidad Nacional de Quilmes (IDES-UNQ). Es autor de Cuando la sangre no seca rápido. Muertes violentas como acontecimientos públicos (EDULP, 2017).

Brenda Focás es Licenciada en Ciencias de la Comunicación, magister en Comunicación y Cultura y doctora en Ciencias Sociales por la Universidad de Buenos Aires (UBA). Es investigadora asistente en el CONICET y se desempeña como profesora e investigadora en el Instituto de Altos Estudios Sociales (IDAES) de la Universidad Nacional de San Martín (UNSAM). Sus investigaciones están centradas en la problematización pública del delito, las percepciones de la inseguridad y el rol de los medios de comunicación. Integra el Núcleo sobre Estudios de Violencia y Muerte y co-coordina el Núcleo en Estudios sobre Comunicación y Cultura del IDAES. Es coeditora junto a Omar Rincón de Inseguridad, medios y miedos, una mirada desde las prácticas y las experiencias en América Latina (ICESI y Fes comunicación, 2016)

\section{REGISTRO BIBLIOGRAFICO}

Galar, S. y Focás, B. (enero-junio, 2018), ¿Víctimas virtuales? Inseguridad, públicos y redes sociales en Argentina. InMediaciones de la Comunicación, 13(1), 241-260 